\title{
Comparative double blind clinical trial of phenytoin and sodium valproate as anticonvulsant prophylaxis after craniotomy: efficacy, tolerability, and cognitive effects
}

\begin{abstract}
L F M Beenen, J Lindeboom, D G A Kasteleijn-Nolst Trenité, J J Heimans, F J Snoek, $\mathrm{D} J$ Touw, $\mathrm{H}$ J Adèr, $\mathrm{H}$ A M van Alphen
\end{abstract}

\begin{abstract}
Objective-To determine the efficacy, tolerability, and impact on quality of life and cognitive functioning of anticonvulsant prophylaxis with phenytoin or sodium valproate in patients after craniotomy.

Methods-A prospective, stratified, randomised, double blind single centre clinical trial was performed, comparing two groups of 50 patients each, who underwent craniotomy for different pathological conditions and who were treated for 1 year after surgery with either $300 \mathrm{mg}$ phenytoin/day or $1500 \mathrm{mg}$ sodium valproate/day. During the study period patients were seen in the outpatient clinic at $1.5,3,6$, and 12 months, when medical history, adverse events, and drug plasma concentrations were evaluated. Neuropsychological functioning and quality of life were assessed on the last three visits. In cases of a seizure an EEG was performed, drug plasma concentration assessed, and medication subsequently increased.
\end{abstract}

Results-Of the 100 included patients 14 (seven in each group) experienced one or more postoperative seizures. Severity of the seizures was comparable in the two groups. In all patients, drug plasma concentrations were in the low or subtherapeutic ranges at the time of the first postoperative seizure. Five patients in the phenytoin group and two in the valproate group had to stop their treatment due to drug related adverse events. Sixty patients completed the 12 month period. Analysis of neuropsychological and quality of life data showed no significant differences.

Conclusion-For efficacy, tolerability, impact on cognitive functioning, and quality of life, no major differences were found between phenytoin and valproate prophylaxis. Valproate is an alternative for anticonvulsant prophylaxis in patients after craniotomy.

(F Neurol Neurosurg Psychiatry 1999;67:474-480)

Keywords: craniotomy; sodium valproate; phenytoin; seizures; quality of life; cognitive functioning

Neurosurgical procedures invading the anterior or middle cranial fossa carry the risk of postoperative epilepsy. ${ }^{12}$ The incidence of epilepsy primarily depends on the underlying pathology; the overall incidence is estimated to be $17 \%$. $^{3}$ Some neurosurgical diseases are related to a relatively high incidence of postoperative seizures - for example, cerebral abcess and head trauma with intracerebral haematoma. ${ }^{47}$ Other specific high risk patient categories are: aneurysmal subarachnoid haemorrhage, ${ }^{89}$ arteriovenous malformation, ${ }^{10}{ }^{11}$ meningioma, ${ }^{12-14}$ and glioma. ${ }^{1516}$ In brain tumours the incidence is roughly inversely related to the degree of malignancy. ${ }^{1516}$ Another important determinant of postoperative epilepsy is the location of the lesion: falx and parasagittal meningiomas have a higher incidence than meningiomas located elsewhere, ${ }^{914} 17$ and aneurysms of the middle cerebral artery carry a higher risk of epilepsy than other aneurysms. ${ }^{18}$ Other known factors of influence for postoperative epilepsy are complications (infection, ischaemia) and the surgical approach to the lesion. ${ }^{9}$

The untoward effects of epilepsy are found in transient or permanent neurological disability and complications in the direct postoperative period. ${ }^{219}{ }^{20}$ Socioeconomic consequences of epilepsy can be severe-for example, occurrence of a seizure may result in the loss of a person's driving licence, ${ }^{21}$ underscoring the importance of preventing seizures when possible.

As prophylaxis after a craniotomy, anticonvulsant drugs should ideally be easy to use, provide adequate control, and generate no major side effects. Especially in postoperative patients sedative effects are unwanted because of interference with adequate diagnosis of postoperative complications such as haemorrhage. Intravenous preparations are necessary during recovery from anaesthesia. In postcraniotomy prophylaxis the most widely used drug today is phenytoin. Until now, reports on the use of sodium valproate for this indication are limited. Price found a control rate of nearly $90 \%$ in 70 neurosurgical patients who previously had at least five seizures/month. ${ }^{22}$ Most required daily doses of less than $2 \mathrm{~g}$ /day of sodium valproate; three patients had to stop treatment due to drug intolerance.

Treatment of epilepsy with sodium valproate in therapeutic doses is thought to produce relatively few cognitive side effects. ${ }^{23} \mathrm{Al}-$ though its superiority in this respect over older drugs such as phenobarbital is well established, the advantage of valproate over phenytoin is less clear. Results of direct comparisons on 
Table 1 Baseline characteristics of study groups

\begin{tabular}{llll}
\hline Parameter & Phenytoin & Valproate & Total \\
\hline No of cases & 50 & 50 & 100 \\
Men/women & $26 / 24$ & $21 / 29$ & $47 / 53$ \\
Mean age/ range (y) & $55 / 21-78$ & $51 / 21-77$ & $53 / 21-78$ \\
Completed 12 months & $29(27)$ & $31(28)$ & $60(55)$ \\
Pathology: & & & \\
$\quad$ Malignant glioma & $7(0)$ & $11(2)$ & $18(2)$ \\
Low grade glioma & $2(1)$ & $1(1)$ & $3(2)$ \\
Metastasis & $9(2)$ & $4(1)$ & $13(3)$ \\
Meningioma & $7(6)$ & $8(7)$ & $15(13)$ \\
Other tumours & $4(4)$ & $4(4)$ & $8(8)$ \\
Traumatic head injury & $2(1)$ & $2(1)$ & $4(2)$ \\
Chronic subdural haematoma & $1(0)$ & $2(2)$ & $3(2)$ \\
Intracranial haemorrhage & $3(2)$ & $1(1)$ & $4(3)$ \\
Aneurysmal SAH & $15(11)$ & $13(5)$ & $28(16)$ \\
Cavernoma & $0(0)$ & $4(4)$ & $4(4)$ \\
\hline
\end{tabular}

* Other brain tumors were a pituitary adenoma, neurocytoma, schwannoma, and a haemangioblastoma in the phenytoin group, and two colloid cysts, a pitiutary adenoma, and a hamartoma in the valproate group. SAH=Subarachnoid haemorrhage. The number of patients with complete cognitive assessment are shown in parentheses.

cognitive function between the last two have been equivocal or slightly in favour of valproate. ${ }^{25-28}$ Possibly a differential effect is clearer in patients with lesions, in whom anticonvulsant medication seems to have more impact on cognition than in patients with idiopathic epilepsy. ${ }^{29}$ However, this may not be easy to assess, as the study of such patients introduces numerous potential confounding factors, such as lesion size and rate of recovery. Nevertheless, the presence of brain damage may interact with type of medication to cause observable differences with respect to neuropsychological test performance or subjective wellbeing.

In view of this possibility it was considered worthwhile to compare cognitive function in neurosurgical patients who were prophylactically treated with either valproate or phenytoin (intravenously and orally), using neuropsychological tests focused on attention, memory, and speed of information processing as well as perceived quality of life. Our aim was to compare the efficacy and tolerability of sodium valproate with phenytoin.

\section{Patients and methods}

DESIGN

A single centre, stratified, randomised, double blind, comparative clinical trial was performed. The procedures followed were approved by the institutional ethics committee, and were in accordance with the Helsinki Declaration of 1975, as revised in 1983. Randomisation started in August 1993 and was stopped after reaching the preset inclusion of 100 patients - 50 patients in each group - in August 1995. Patients were stratified depending on the type of their intracranial pathology: brain tumour, trauma, or vascular lesions. Random allocation was carried out with sealed envelopes for each stratum, each patient receiving a separate treatment number determining whether the patient was treated with phenytoin or valproate. Sanofi Winthrop Recherche, Montpellier, France provided all precoded packaged material.

CRITERIA FOR INCLUSION

Patients could be included if they would undergo supratentorial surgery for one of the above mentioned pathological conditions, were aged between 18 and 80 years, and had given written informed consent. Exclusion criteria were: a life expectancy of less than 6 months, preoperative use of anticonvulsant drugs for more than 3 months, a history of epileptic seizures apart from seizures caused by the presenting disease (this was the case in 23 patients, most of whom had a glioma), chronic use of psychopharmaceuticals, alcohol or drug misuse, severe psychiatric illness, and participation in an experimental drug trial. The demographic data of the included patients are presented in table 1 . In view of the few trauma cases, the strata were collapsed to two categories (tumour $v$ other).

DRUG TREATMENT

Intravenous administration of $100 \mathrm{mg}$ phenytoin thrice daily or $500 \mathrm{mg}$ valproate thrice daily was started immediately postoperatively in the recovery room. We did not use loading doses. As soon as possible, patients switched to the same regimen in oral formulation of phenytoin or valproate (Depakine chrono ${ }^{\circledR}$ ). In selected cases of critically ill patients with a long stay in the intensive care unit, medication was administered as syrup via a nasogastric tube. No other maintenance anticonvulsant medication, including barbiturates, hypnotics, and benzodiazepines, was acceptable during the study. Otherwise, the patient was withdrawn from the study and considered a treatment failure.

In cases of adverse events, intoxication or toxic drug plasma concentrations $(\geqslant 200 \mathrm{mg} / \mathrm{l}$ valproate and $50 \mathrm{mg} / 1$ phenytoin) the medication regimen was adjusted at the judgement of the unblinded investigator (DGAK), who was not otherwise involved in the data collection. Subsequent control plasma concentrations were taken. In case of a seizure a detailed description of the event was obtained to classify it according to the ILAE international classification and elaborate its severity according to the national hospital seizure severity score NHS3. ${ }^{30}{ }^{31}$ If possible, a drug plasma concentration was taken, an EEG was performed, and medication was adjusted.

PHARMACOKINETIC CALCULATIONS

Average individual steady state serum concentrations were calculated using the population pharmacokinetic software programme $\mathrm{MW} /$ Pharm with general population models for phenytoin and valproic acid. ${ }^{32}$ Models were fit to the patient data (weight, height, age) and serum concentration data using Bayesian regression to obtain the individual pharmacokinetic parameters (phenytoin: volume of distribution and elimination rate constant). These individualised pharmacokinetic parameters were used to calculate individual steady state serum concentrations.

\section{ASSESSMENTS}

During the recovery period, vital signs, adverse events, and a drug plasma concentration on the third postoperative day were assessed. Patients were followed up for 1 year, during which 
period they were controlled by the study coordinator (LFMB) at the outpatient clinic at 1.5, 3, 6, and 12 months for: medical history including possible seizures and adverse effects of the anticonvulsant, physical examination, Karnofsky performance status, and laboratory tests including drug plasma concentration. At 3 , 6, and 12 months neuropsychological and quality of life tests were administered.

NEUROPSYCHOLOGICAL TESTS

Neuropsychological tests consisted of two standard clinical tasks and three computerised tasks; the last were derived from a battery designed for the testing of epileptic patients and have been shown to be useful in the study of anticonvulsant drugs. ${ }^{33-35}$

\section{(1) Serial word learning ${ }^{36}$}

The learning of a list of 15 orally presented words is measured by immediate recall (sum of 5 trials), delayed recall after an interval of 20 minutes, and recognition (yes/no choice in a list of 30 words).

(2) Categoric word fluency, derived from a Dutch intelligence test ${ }^{37}$

The patient is required to name as many animals and professions as possible, one minute each.

\section{(3) Simple auditory reaction time}

The space bar must be pressed as fast as possible with the preferred hand in response to an auditory stimulus. Performance is measured as the median reaction time in 30 trials.

\section{(4) Binary choice task}

The patient must press a left or right key in response to respectively a green square on the left side and a red square on the right side of the screen, appearing in random alternation. Each response is immediately followed by a new stimulus. Performance is measured by the average reaction time in 60 trials.

\section{(5) Visual searching task}

A non-verbal design in the centre of the screen must be matched to one out of 24 surrounding patterns. Performance is measured by the average search time in 24 trials.

The Dutch version of the National adult reading test, ${ }^{38}$ a measure of vocabulary insensitive to brain dysfunction, ${ }^{39}$ was administered on the visit at 3 months to estimate premorbid intelligence.

\section{QUALITY OF LIFE MEASURES}

Emotional status was measured with a shortened Dutch version of the profile of mood states (POMS) ${ }^{40}{ }^{41}$ which yields five subscales: depression, anger, fatigue, vigour, and tension. Fatigue was additionally assessed with the more extensive fatigue severity scale (FSS). ${ }^{42}$ Furthermore, a self developed questionnaire was administered, previously employed in a study in patients with low grade glioma, ${ }^{43}$ referring to perceived dependency in activities of daily living (six three point items), physical complaints (seven three point items), cognitive restrictions (five five point items), sense of restriction in daily functioning (one five point item), satisfaction with health (one five point item), and general wellbeing (one five point item).

\section{ANALYSIS}

At the end of the study, recorded variables for each individual patient were elaborated and analysed. Outcome measurements for the study were: efficacy as determined by the occurrence of seizures and their severity score following the national hospital seizure severity score, clinical tolerability, cognitive functioning evaluated by neuropsychological tests, and quality of life. For efficacy, seizure severity, and tolerability, group differences were tested with $t$ tests and non-parametric tests ( $\chi^{2}$ or Fisher's exact, Mann-Whitney $U$ test) as appropriate. Neuropsychological and quality of life data were analysed with repeated measurements analysis of variance (ANOVA), using polynomial contrasts. Independent variables were group (phenytoin $v$ valproate) and stratum (tumour $v$ other). The outcomes consideredreflecting possible differential medication effects-were the overall group difference (phenytoin $v$ valproate) and the linear or quadratic group by visit interaction. This analysis was restricted to 55 patients who could be fully tested on all three occasions (table 1), which excluded 11 patients who were tested partially and 24 who could not be tested at all. Due to a high mortality, the excluded group contained most patients with high grade gliomas or metastatic tumours. A power analysis indicated that, given the design and group size, the statistical power to show significance for a difference of $0.5 \mathrm{SD}$ at the two tailed 5\% level was 0.87 . Significance was accepted at the two tailed 5\% level.

\section{Results}

DEMOGRAPHY

No significant differences were found in baseline characteristics (sex, age, pathology, and history of preoperative seizures) of the medicine groups, either in the total sample or in the subgroups with complete neuropsychological and quality of life data. The estimated premorbid IQ was distributed equally (phenytoin: 101 (SD 14), valproate: 100 (SD 14) in the last two. Causes of drop out are listed in table 2 . The mortality rate tended to be higher in tumour patients with phenytoin than in those with valproate $(43 \% v 18 \%)$, but the difference did not reach significance $\left(\chi^{2}=3.04\right.$, $\mathrm{p}<0.10)$. In other patients there was a nonsignificant opposite tendency (phenytoin 5\% mortality, valproate $23 \%$; $=0.19$, Fisher's exact test).

\section{EFFICACY}

Postoperative seizures occurred in both the phenytoin group and the valproate group in seven patients (table 3). The time of occurrence of the first seizure is shown in the figure. In both groups two patients had their first seizure on the day of operation. No difference was 
Table 2 Attrition by medicine group and stratum

\begin{tabular}{|c|c|c|c|c|}
\hline & \multicolumn{2}{|c|}{ Phenytoin } & \multicolumn{2}{|l|}{ Valproate } \\
\hline & Tumour & Other & Tumour & Other \\
\hline Completed trial & 13 & 16 & 16 & 15 \\
\hline Died in week 1 & 1 & 0 & 1 & 0 \\
\hline $2-6$ & 2 & 1 & 1 & 1 \\
\hline $7-12$ & 2 & 0 & 1 & 0 \\
\hline $13-26$ & 3 & 0 & 0 & 4 \\
\hline $27-52$ & 4 & 0 & 2 & 0 \\
\hline Intercurrent illness & 2 & 1 & 3 & 0 \\
\hline Adverse drug reaction & 1 & 4 & 2 & 0 \\
\hline Needed concomitant medication & 0 & 0 & 2 & 0 \\
\hline Withdrew informed consent & 0 & 0 & 0 & 1 \\
\hline Lost to follow up & 0 & 0 & 0 & 1 \\
\hline
\end{tabular}

Table 3 Cases with seizures

\begin{tabular}{llll}
\hline & Phenytoin & Valproate & Total \\
\hline Preoperative & 11 & 12 & 23 \\
Simple partial & 2 & 2 & 4 \\
Generalised & 9 & 9 & 18 \\
Simple partial and generalised & 0 & 1 & 1 \\
Postoperative & $7(2)$ & $7(3)$ & $14(5)$ \\
Simple partial & $3(1)$ & $2(1)$ & $5(2)$ \\
Generalised & $2(1)$ & $4(2)$ & $6(3)$ \\
Simple partial and generalised & $2(0)$ & $1(0)$ & $3(0)$ \\
Pathology associated with postoperative & seizures: & & $5(1)$ \\
Malignant glioma & $2(1)$ & $3(0)$ & $2(1)$ \\
Metastasis & $2(1)$ & 0 & $2(1)$ \\
Low grade glioma & $1(0)$ & $1(1)$ & $1(1)$ \\
Meningioma & 0 & $1(1)$ & $1(0)$ \\
Neurocytoma & $1(0)$ & 0 & $1(1)$ \\
Cavernoma & 0 & $1(1)$ & $1(0)$ \\
Traumatic head injury & $1(0)$ & 0 & $1(0)$ \\
Aneurysm ant comm artery & 0 & $1(0)$ & \\
\hline
\end{tabular}

The number of patients with postoperative seizures who also had preoperative seizures are shown in parentheses. therapeutic range $(<8 \mathrm{mg} / \mathrm{l}$ phenytoin, $<50 \mathrm{mg} / 1$ valproate) in all seven patients of the phenytoin group and four out of the seven patients in the valproate group; in the other three valproate patients drug concentrations were below 62 $\mathrm{mg} / \mathrm{l}$. In the 10 patients whose first seizure occurred more than 1 day after the operation, the mean drug plasma concentrations were 5.1 (SD 2.3) $\mathrm{mg} / \mathrm{l}$ for those on phenytoin $(\mathrm{n}=5)$ and 56.8 (SD 10.0) $\mathrm{mg} / \mathrm{l}$ for those on valproate $(n=5)$. In patients without postoperative seizures these values were 11.7 (SD 6.7) (phenytoin, $n=43$ ) and 70 (SD 13) (valproate, $n=43$ ), both significantly higher $(\mathrm{p}<0.05, t$ test). For the total sample, excluding patients with a change in medication, the steady state concentrations of phenytoin and valproate were 10.9 (SD 6.6) $\mathrm{mg} / \mathrm{l}$ (range 4-28) and 68 (SD 13) $\mathrm{mg} / 1$ (range 44-100) respectively.

DOSAGE REGIMEN CHANGES

The initial therapy regimen of tablets thrice daily remained unchanged in 81 patients, 38 of them receiving phenytoin, 43 of them taking valproate. Significantly more patients on phenytoin had to reduce their drug regimen to twice daily because of toxic drug plasma concentrations, seven out of 50 patients on phenytoin compared with no patients out of 50 on valproate ( $p=0.012$, Fisher's exact test). In five patients receiving phenytoin and in seven patients receiving valproate dosages had to be increased after seizures.

One patient in the phenytoin group and two in the valproate group experienced a single seizure (with seizure freeedom after change of dosage). The other 11 patients had multiple seizures despite increased dosages. Subtherapeutic dosages were in themselves no reason to increase the dosage, whereas toxic dosages were.

\section{ADVERSE EFFECTS}

Seven patients had to stop treatment because of drug related side effects, five patients in the phenytoin group versus two in the valproate group (not significant). Four patients treated with phenytoin showed a hypersensitivity skin reaction, occurring between 6 days and 4 weeks after the start of treatment. After cessation of the therapy recovery of the patients was without sequelae within 1-2 weeks. In both study groups patients had transient gastrointestinal complaints. In one patient treated with phenytoin the nausea was persistent despite treatment with several antiemetics, and caused withdrawal from the trial. Also in both groups equal numbers of liver function disturbances were found (total number of patients six). In one patient treated with valproate there was a marked rise in liver enzymes which necessitated withdrawal from the trial. A contributing factor could have been the pre-existent minor disturbance of liver function associated with the use of amiodarone. In all patients liver enzymes returned to normal values, without lasting consequences to the patients. In one patient receiving valproate a thrombopenia necessitated discontinuation of treatment. Other known adverse effects of the 


\begin{tabular}{|c|c|c|c|c|c|c|c|c|c|c|c|c|}
\hline & \multicolumn{4}{|c|}{3 Months } & \multicolumn{4}{|c|}{6 Months } & \multicolumn{4}{|c|}{12 Months } \\
\hline & \multicolumn{2}{|c|}{ Phenytoin } & \multicolumn{2}{|c|}{ Valproate } & \multicolumn{2}{|c|}{ Phenytoin } & \multicolumn{2}{|c|}{ Valproate } & \multicolumn{2}{|c|}{ Phenytoin } & \multicolumn{2}{|c|}{ Valproate } \\
\hline & $M$ & $S D$ & $M$ & $S D$ & $M$ & $S D$ & $\bar{M}$ & $S D$ & $M$ & $S D$ & $M$ & $S D$ \\
\hline Word learning, immediate recall & 34.7 & 13.8 & 37.8 & 11.0 & 39.0 & 15.7 & 41.9 & 10.9 & 40.6 & 17.2 & 47.3 & 12.6 \\
\hline Word learning, delayed recall & 6.5 & 4.0 & 7.3 & 3.3 & 8.0 & 4.1 & 8.1 & 3.1 & 7.9 & 4.4 & 9.3 & 3.7 \\
\hline Word learning, recognition & 27.1 & 3.4 & 27.8 & 1.7 & 27.1 & 3.0 & 28.1 & 2.5 & 27.3 & 3.8 & 28.7 & 2.7 \\
\hline Word fluency & 32.2 & 13.2 & 36.4 & 12.2 & 35.4 & 13.5 & 37.2 & 10.7 & 36.9 & 13.2 & 37.1 & 12.7 \\
\hline Auditory reaction time (ms) & 347 & 247 & 328 & 189 & 320 & 170 & 252 & 72 & 323 & 282 & 268 & 94 \\
\hline Binary choice (ms) & 660 & 446 & 580 & 219 & 647 & 516 & 548 & 230 & 570 & 241 & 579 & 248 \\
\hline Visual search $(\mathrm{s})$ & 23.0 & 18.1 & 20.0 & 15.7 & 20.1 & 14.8 & 21.3 & 21.0 & 19.9 & 13.9 & 19.9 & 21.2 \\
\hline
\end{tabular}

The data are derived from 55 patients (27 with phenytoin, 28 with valproate) whose assessment was complete.

anticonvulsant drugs-for example, weight gain with valproate and anaemia with phenytoin - were minor and did not necessitate cessation of trial medication.

\section{NEUROPSYCHOLOGICAL TESTS AND QUALITY OF LIFE}

In a preliminary analysis, patients who were available for psychological assessment after 3 months but not after 12 months $(n=11)$ were compared with patients who were assessed on all three occasions $(n=55)$. The first had a higher mean age $(\mathrm{p}=0.03, t$ test $)$ and scored on average lower on immediate recall $(p=0.007)$ and word fluency $(p=0.009)$ on the first assessment; their rating of general wellbeing was also lower $(p=0.050)$ but other differences on quality of life measures were not significant.

In patients with complete data, the analysis of neuropsychological test results disclosed no significant differences between the phenytoin and valproate groups. As table 4 shows, the averages generally favoured the valproate group, but the differences failed to reach significance because the SDs were large. Moreover, the interpretation of the learning test results is complicated by significant group by stratum interactions on all three measures, immediate recall $(\mathrm{p}=0.006)$, delayed recall $(p=0.015)$ and recognition $(p=0.005)$. In the phenytoin group tumour patients tended to score higher than other patients, but in the valproate group lower. For quality of life, valproate patients tended to rate themselves as less vigorous and more tired and tense than phenytoin patients, especially at the 6 month visit (table 5). However, the only significant effect was a quadratic group by visit interaction on the POMS tension scale ( $\mathrm{p}=0.008)$.

\section{Discussion}

Despite the frequent occurrence of seizures after a craniotomy the routine use of anticonvulsant drugs as prophylaxis is controversial. Anticonvulsant prophylaxis for the prevention of seizures is recommended in general if the risk of seizures exceeds $10 \%-15 \%$, which is the anticipated incidence of serious adverse drug effects. ${ }^{1}$ Prophylaxis is also advised when a single seizure may have disastrous consequences or when seizures are a major impediment to a patient's return to normal activity.

The choice of anticonvulsant prophylaxis should be determined on one hand by the risks and consequences of seizures during the immediate postoperative period and during the later course, and on the other hand by the efficacy and tolerability of each anticonvulsant drug. Furthermore, it should still be determined when to start and withdraw prophylactic medication and what dosages should be prescribed.

In this study, a randomised clinical trial evaluating the clinical impact of two widely used anticonvulsants as prophylaxis after craniotomy, we found no significant differences in efficacy and tolerability between the two treatment groups: both in the phenytoin group and the sodium valproate group the same number of patients had seizures. In both groups the seizures also had the same severity impact on patients.

Our data are comparable with the data from the double blind randomised trial carried out by North $e t a l^{44}$ who had a similar study population and follow up of 1 year. In 281 postcraniotomy patients they compared 100 mg phenytoin thrice daily with placebo. Phenytoin significantly reduced seizure incidence

Table 5 Quality of life measures

\begin{tabular}{|c|c|c|c|c|c|c|c|c|c|c|c|c|}
\hline & \multicolumn{4}{|c|}{3 Months } & \multicolumn{4}{|c|}{6 Months } & \multicolumn{4}{|c|}{12 Months } \\
\hline & \multicolumn{2}{|c|}{ Phenytoin } & \multicolumn{2}{|c|}{ Valproate } & \multicolumn{2}{|c|}{ Phenytoin } & \multicolumn{2}{|c|}{ Valproate } & \multicolumn{2}{|c|}{ Phenytoin } & \multicolumn{2}{|c|}{ Valproate } \\
\hline & $M$ & $S D$ & $M$ & $S D$ & $M$ & $S D$ & $M$ & $S D$ & $M$ & $S D$ & $M$ & $S D$ \\
\hline POMS Depression & 4.8 & 6.5 & 4.8 & 6.2 & 3.6 & 5.6 & 4.2 & 4.8 & 5.5 & 7.3 & 4.5 & 5.3 \\
\hline Tension & 5.7 & 5.9 & 7.6 & 5.9 & 3.4 & 3.6 & 8.0 & 6.1 & 4.6 & 4.7 & 6.9 & 5.4 \\
\hline Vigour & 11.3 & 4.8 & 10.6 & 4.0 & 13.3 & 3.8 & 10.0 & 4.7 & 12.1 & 4.0 & 10.2 & 4.4 \\
\hline Anxiety & 5.2 & 4.9 & 4.3 & 5.1 & 3.7 & 4.2 & 4.2 & 5.1 & 5.3 & 5.3 & 4.8 & 4.7 \\
\hline Fatigue & 5.6 & 5.7 & 5.4 & 5.0 & 3.2 & 2.6 & 5.9 & 4.9 & 4.5 & 4.1 & 5.6 & 5.0 \\
\hline Fatigue severity scale & 33.8 & 16.6 & 37.6 & 13.3 & 29.6 & 11.7 & 37.2 & 13.0 & 33.4 & 13.4 & 3.7 & 15.9 \\
\hline Physical complaints & 10.0 & 2.3 & 10.4 & 2.5 & 9.5 & 1.3 & 10.0 & 1.8 & 10.0 & 2.0 & 9.9 & 2.3 \\
\hline ADL dependency & 8.2 & 1.8 & 8.9 & 3.4 & 7.3 & 1.5 & 8.0 & 2.5 & 7.1 & 1.3 & 7.7 & 2.3 \\
\hline Cognitive complaints & 9.2 & 4.3 & 8.3 & 3.0 & 7.5 & 2.9 & 7.9 & 2.1 & 8.3 & 3.2 & 8.1 & 2.7 \\
\hline Impediment of daily functioning & 2.5 & 1.0 & 2.4 & 1.1 & 2.1 & 0.9 & 2.0 & 0.9 & 2.3 & 1.0 & 2.1 & 1.1 \\
\hline Satisfaction with health & 3.3 & 1.0 & 3.1 & 1.0 & 3.3 & 0.9 & 3.7 & 0.8 & 3.3 & 0.9 & 3.6 & 0.7 \\
\hline General wellbeing & 3.1 & 0.9 & 3.1 & 1.2 & 3.8 & 0.9 & 3.7 & 1.0 & 3.6 & 0.9 & 3.8 & 0.8 \\
\hline
\end{tabular}

The data are derived from 55 patients ( 27 with phenyroin, 28 with valproate) whose assessment was complete. ADL=Activities of daily living. 
(18 $v 26$ patients $=12.9 \% v 18.4 \%)$ with highest protection between days 7 and 72 . The incidence in their treatment group compares well with the $14 \%$ seizure incidence we found in both our study groups. In another randomised trial, ${ }^{45}$ Foy et al compared phenytoin or carbamazepine treatment with placebo for a period of 6 or 24 months and found a reduction of almost $10 \%$ in postoperative seizures in the anticonvulsant groups. The differences were not statistically significant, but confidence limits were relatively wide. Because no formulation of carbamazepine for intravenous use exists, this limits its use to patients who are able to swallow and have reliable gastrointestinal absorption. A difference with our trial set up was the absence of regular drug monitoring in their patients. In the 217 patients $(80 \%)$ in whom some concentrations were monitored, concentrations of carbamazepine usually were within the therapeutic range, but - as in our study - a significant proportion of phenytoin concentrations were below the therapeutic range.

Our standard treatment regimen of $100 \mathrm{mg}$ phenytoin or $500 \mathrm{mg}$ valproate three times daily resulted in average blood concentrations of $11.7 \mathrm{mg} / 1$ and $57 \mathrm{mg} / \mathrm{l}$ respectively in patients without seizures (most patients); the patients who experienced seizures had significant lower blood concentrations. North et al ${ }^{44}$ also stress the importance of achieving therapeutic anticonvulsant concentrations. In their trial, seven of the nine patients experiencing generalised convulsions had subtherapeutic drug concentrations. By contrast with our findings, in which most patients irrespective of seizure type had serum drug concentrations below the regular therapeutic ranges, North et al found a therapeutic concentration in seven of nine patients with focal seizures. Because both phenytoin and valproate are effective in preventing partial as well as generalised tonic-clonic seizures, ${ }^{45}$ these differences in protection between these seizure types cannot be easily explained.

Seizures in the immediate postoperative period are correlated with the preoperative lesion, the site of the lesion, postoperative lesions, and subtherapeutic drug concentration. $^{2046}$ We started treatment directly postoperatively when patients arrived at the recovery room. Six patients experienced their first seizure during the first postoperative week, four had a first seizure already at the day of the operation. In one patient the seizure was associated with a postoperative haemorrhage.

In a placebo controlled randomised trial on phenytoin Lee et $a l^{19}$ studied immediate and early seizures in 374 patients. During the first 3 days, 11 patients $(2.9 \%)$ developed seizures: two in the phenytoin group and nine in the placebo group; this difference was not significant. Because $80 \%$ of the immediate seizures occurred within 20 minutes after surgery they recommended anticonvulsant drugs to be given at least 20 minutes before completion of wound closure. The advised therapeutic loading dose for phenytoin varies between $7-10$ $\mathrm{mg} / \mathrm{kg} .{ }^{47}{ }^{48}$ For sodium valproate a schedule of an intravenous $10 \mathrm{mg} / \mathrm{kg}$ bolus and $0.6 \mathrm{mg} / \mathrm{kg} /$ hour sodium valproate is advised. ${ }^{49}$ Because these anticonvulsant drugs need about 1 week to reach a steady state drug plasma concentration, an even better option could be to start 1 week preoperatively, whenever possible, as was advised by North et al. ${ }^{44}$

In our study, nine (64\%) of the 14 patients who experienced seizures had their first seizure within 3 months after the operation. Of the 76 patients at risk at 3 months, five $(7 \%)$ had their seizure presentation within 6 months. These findings are in line with the data from North $e t$ $a l,{ }^{44}$ in which three quarters of all seizures occurred within 3 months. With a longer follow up, the incidence in postoperative seizures increases depending on the underlying pathology: in cerebral abscess, first year incidence was $30 \%$, rising to $72 \%$ after a median follow up of 11 years. ${ }^{50}$ Although some authors advocate prophylaxis during one to several years, ${ }^{51}$ in the long term, the benefits of seizure prevention may not outweigh the risks of chronic anticonvulsant use. Our study supports the idea of stopping prophylaxis after a 6 month period. Further elucidation on this matter should be obtained by a prospective study.

For toxicity and adverse effects, in our study more patients had to stop treatment due to toxicity in the phenytoin group than in the valproate group (five phenytoin $v$ two valproate). The $8 \%$ incidence of hypersensitive skin reactions associated with phenytoin use we found is well comparable with the literature. ${ }^{52}$ Other known adverse effects of both anticonvulsant drugs - for example, gastrointestinal complaints, liver function disturbances, anaemia (phenytoin), and weight gain (valproate) were comparable with data reported in the literature $\mathrm{e}^{21} 53$ and were in most cases of minor impact. Only in two patients (one in each group) did it necessitate cessation of trial medication.

With respect to the psychological evaluation, patients with valproate showed a slight but consistent advantage on cognitive measures, whereas they tended to complain more of tension and fatigue. Whether larger group sizes would have led to significant differences is doubtful. It must be taken into account that the patients had varied and often severe brain disease, and it is unlikely that the severity of the cognitive effects was entirely equated by the randomisation procedure. In this respect an increase in group sizes might well lead to smaller differences. At any rate the differential effect of phenytoin and valproate on cognition and quality of life seems negligible in comparison with the impact of disease and its treatment.

In conclusion, we compared two regularly used anticonvulsant drugs with both oral and intravenous formulation at standard dosages. No difference in either efficacy or impact on cognitive functioning and quality of life was found between the two drugs. In favour of valproate was the lower number of patients showing toxic serum drug concentrations. Both drugs can be recommended for the use of postoperative prophylaxis. For protection of 
immediate postoperative seizures it is advised to start treatment 1 week before surgery, or if that is not possible to start treatment with a loading dose at least 20 minutes before wound closure.

A timely detection and adjustment of subtherapeutic concentrations is important; this requires frequent monitoring of blood concentrations, starting in the first postoperative week. The anticonvulsant prophylaxis can be stopped after 6 months.

Part of this study was presented at the 11th International Congress of Neurological Surgery, held 4-11 July 1997 in Amsterdam, The Netherlands. Drugs and an unrestricted educational grant were supplied by Sanofi Winthrop v o f, Govert van Wijnkade 48, 3144 EG Maassluis, The Netherlands.

1 Deutschman CS, Haines SJ. Anticonvulsant prophylaxis in neurological surgery. Neurosurgery 1995;7:510-17.

2 North JB. Anticonvulsant prophylaxis in neurosurgery. $\mathrm{Br} \mathcal{F}$ Neurosurg 1989;3:425-7.

3 Foy PM, Copeland GP, Shaw MDM. The incidence of postoperative seizures. Acta Neurochir 1981;55:253-64

4 Bidzinski J, Koszewski W. The value of different methods of treatment of brain abscess in the CT era. Acta Neurochir 1990;105:117-20.

5 Legg NJ, Gupta PC, Scott DF. Epilepsy following cerebral abscess. A clinical and EEG study of 70 patients. Brain 1973;96:259-68.

6 Northcroft GB, Wyke BD. Seizures following surgical treatment of intracranial abscesses, a clinical and electroenment of intracranial abscesses, a clinical and electr.

7 Jennett, B. Epilepsy after non-missile head injuries. 2nd ed. London: Wm Heiman Medical Books, 1975.

8 Sundt TM jr, Kobayashi S, Fode NC, et al. Results and complications of surgical management of 809 intracranial aneurysms in 722 cases. Related and unrelated to grade of patient, type of aneurysm, and timing of surgery. $\mathscr{f}$ Neurosurg 1982;56:753-65.

9 Cabral RJ, King TT, Scott DF. Epilepsy after two different neurosurgical approaches to the treatment of ruptured intracranial aneurysm. F Neurol Neurosurg Psychiatry 1976; 39:1052-6.

10 Forster DMC, Steiner L, Hakanson S. Arteriovenous malformations of the brain; a long term clinical study. $f$ Neurosurg 1972;37:562-70.

11 Parkinson D, Bachers G. Arteriovenous malformations. Summary of 100 consecutive supratentorial cases. F Neurosurg 1980;53:85-99.

12 Chozick BS, Reinert SE, Greenblatt SH. Incidence of seizures after surgery for supratentorial meningeomas: a seizures after surgery for supratentorial menin

13 Giombini S, Solero CL, Lasio G, et al. Immediate and late outcome of operations for parasagittal and falx meningiomas. Surg Neurol 1984;21:427-35.

14 Ramamurthi B, Ravi R, Ramachandran V. Convulsions with meningiomas: incidence and significance. Surg Neurol 1980;14:415-416

15 Moots PL, Maciunas RJ, Eisert DR, et al. The course of seizure disorders in patients with malignant gliomas. Arch Neurol 1995;52:717-24.

16 Boarini DJ, Beck DW, VanGilder JC. Postoperative prophylactic anticonvulsant therapy in cerebral gliomas. Neurosurgery 1985;16:290-2.

17 Chan RC, Thompson GB. Morbidity, mortality and quality of life following surgery for intracranial meningeomas. $\mathcal{F}$ Neurosurg 1984;60:52-60.

18 Keranen T, Tapaninaho A, Hernesniemi J, et al. Late epilepsy after aneurysm operations. Neurosurgery 1985;17: 897-900.

19 Lee ST, Lui TN, Chang CN, et al. Prophylactic anticonvulsants for prevention of immediate and early postcraniotomy seizures. Surg Neurol 1989;31:361-4.

20 Fukamachi A, Koizumi H, Nukui H. Immediate postoperative seizures: incident and computed tomographic findings. Surg Neurol 1985;24:671-6.

21 Dreifuss FE. Prevention as it pertains to epilepsy. Arch Neurol 1995;52:363-06.

22 Price DJE. The advantages of sodium valproate in neurosurgical practice. In: Legg NJ, ed. Clinical and pharmacological aspects of sodium valproate in the treatment of epilepsy. Kent: MCS Consultants; 1976:44-49.

23 Gillham RA, Read CL, McKee PJW, et al. Cognitive function in adult epileptic patients on long-term sodium valproate. F Epilepsy 1991;4:205-10.

24 Devinsky 0. Cognitive and behavioral effects of antiepileptic drugs. Epilepsia 1995;36(suppl 2):46-65.

25 Craig I, Tallis R. Impact of valproate and phenytoin on cognitive function in elderly patients: results of a single-blind nitive function in elderly patients: results of a single-blind
randomized comparative study. Epilepsia 1994;35:381-90.

26 Meador KJ, Loring DW, Moore EE, et al. Comparative cognitive effects of phenobarbital, phenytoin, and valproate in healthy adults. Neurology 1995;45:1949-99.
27 Trimble MR, Thompson PJ. Anticonvulsant drugs, cognitive function, and behavior. Epilepsia 1983;24(suppl 1):5563.

28 Forsythe I, Butler R, Berg I, et al. Cognitive impairment in new cases of epilepsy randomly assigned to carbamazepine, phenytoin, and sodium valproate. Dev Med Child Neurol 1991;33:524-35.

29 Helmstaedter C, Wagner G, Elger CE. Differential effects of first antiepileptic drug application on cognition in lesional and non-lesional patients with epilepsy. Seizure 1993;2: $125-30$.

30 Commission on classification and terminology of the international league against epilepsy. Proposal for revised classification of epilepsies and epileptic syndromes. Epilepsia 1989;30:389-99.

31 O'Donoghue MF, Duncan JS, Sander JWAS. The national hospital seizure severity scale: a further development of the Chalfont seizure severity scale. Epilepsia 1996;37:563-71.

32 Proost, JH, Meier, DKF. MW/Pharm, an integrated software package for drug dose regimen calculation and therapeutic drug monitoring. Comput Biol Med 1992;22: 155-63.

33 Moerland MC, Aldenkamp AP, Alpherts WCJ. Computerized psychological testing in epilepsy. In: Maarse FJ, Mulder LJM, Sjouw, WPB, et al, eds. Computers in psychology: methods, instrumentation and psychodiagnostics. Lisse: Swets and Zeitlinger, 1988:157-64.

34 Aldenkamp AP, Alpherts WCJ, Moerland MC, et al. Cognitive side-effects in patients with epilepsy. Epilepsia 1987;28: $507-14$

35 Alpherts WCJ, Aldenkamp AP, Moerland MC. An experimental benzodiapine derivate. Effects on cognitive functioning in patients with epilepsy. Prog Neuropsychopharmacol Biol Psychtatry 1987;11:673-82.

36 Heslinga $\mathrm{H}$, van den Burg W, Saan RJ. De nieuwe 15-woordentest $A$ en $B$ in een gezonde populatie (the new 15-words test in a healthy population) [unpublished doctoral thesis]. Groningen, The Netherlands: University of Groningen, 1983.

37 Luteijn F, van der Ploeg FAE. Handleiding Groninger Intelligentietest (Groningen intelligence test, manual). Lisse: Swets and Zeitlinger, 1983.

38 Schmand B, Lindeboom J, van Harskamp F. De Nederlandse Leestest voor Volwassenen. Handleiding (Dutch adult reading test manual). Lisse: Swets and Zeitlinger 1992.

39 Nelson HE. The revised national adult reading test. Test manual. Windsor: NFER-Nelson, 1991.

40 Wald FDM, Mellenbergh GJ. De verkorte versie van de Nederlandse vertaling van de Profile of Mood States (POMS). (The shortened version of the Dutch translation of the POMS). Nederlands Tijdschrift voor Psychologie 1990; 45:86-90.

41 McNair DM, Lorr M, Droppleman LF. Edits manual for the profile of mood states. San Diego: Educational and Industrial Testing Service, 1971

42 Krupp LB, LaRocca NG, Muir-Nash J, et al. The fatigue severity scale; application to patients with multiple sclerosis and systemic lupus erythematosus Arch Neurol 1989;46: 1121-3.

43 Taphoorn MBJ, Klein Schiphorst A, et al. Cognitive functions and quality of life in patients with lowgrade gliomas:the impact of radiotherapy. Ann Neurol 1994;36: gliomas.

44 North JB, Penhall RK, Hanieh A, et al. Phenytoin and postoperative epilepsy. A double-blind study. $\mathcal{F}$ Neurosurg 1983; 58:672-7.

45 Brodie MJ, Dichter MA. Antiepileptic drugs. $N$ Engl f Med 1996;334:168-75.

46 Foy PM, Chadwick DW, Rajgopalan N, et al. Do prophylactic anticonvulsant drugs alter the pattern of seizures after craniotomy? F Neurol Neurosurg Psychiatry 1992;55:753-7.

47 Kvam DA, Loftus CM, Copeland B, et al. Seizures during the immediate postoperative period. Neurosurgery 1983;12: $14-17$.

48 Milde LN, McDonald MG. Therapeutic loading dose of the phenytoin in anesthatized patients. $\mathcal{F}$ Neurosurg Anesthesiol 1989;1:73-5.

49 Tsolaki M, Yannacou-Peftoulidou M, Grammaticos P, et al. Phenytoin plasma levels after intraoperative administration, for the prevention of post-craniotomy seizures. Acta Neurochir (Wien) 1987;84:36-8.

50 Moore AJ, Bell BA, Berry DJ. Intravenous sodium valproate in neurosurgery: repeat dose pharmacinetic study and safety assessment in neurosurgical patients. Proceedings of the 4th international symposium on sodium valproate and epilepsy.

51 Prior P, Legg NJ, Scott DF. Epilepsy following intracranial surgery. In: Proceedings of the 5th European Symposion on Epilepsy. London: International Bureau for Epilepsy; 1973:9498.

52 Krall RL. Prophylactic antiepileptic drugs after brain surgery. Semin Neurol 1981;1:222-4.

53 Haruda F. Phenytoin hypersensitivity: 38 cases. Neurology 1979;29:1480-5.

54 Bruni J. Phenytoin. Toxicity. In: Levy RH, Mattson RH, Meldrum BS, eds. Antiepileptic drugs. 4th ed. New York: Meldrum Raven Press; 1995:345-50. 